\title{
Case Report: Lifelong Idiopathic Unilateral Diaphragmatic Paralysis With Recurrent Pneumonia: A Case Report
}

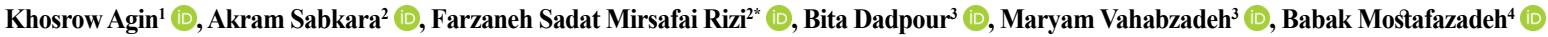 \\ 1. Pulmonologist and Pulmonary Critical Care, Shahid Beheshti University of Medical Sciences, Loghman Hakim General Teaching Hospital, Tehran, Iran. \\ 2. Internal Medicine Resident, Shahid Beheshti University of Medical Sciences, Logman Hakim General Teaching Hospital, Tehran, Iran. \\ 3. Medical Toxicology Research Center, Mashhad University of Medical Sciences, Mashhad, Iran. \\ 4. Toxicological Research Center, Shahid Beheshti University of Medical Sciences, Tehran, Iran.
}

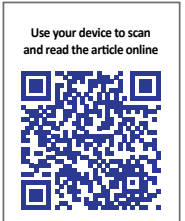

Citation: Khosrow Agin, Akram Sabkara, Farzaneh Sadat Mirsafai Rizi, Bita Dadpour, Maryam Vahabzadeh, Babak Mostafazadeh. Lifelong Idiopathic Unilateral Diaphragmatic Paralysis With Recurrent Pneumonia. International Journal of Medical Toxicology and Forensic Medicine. 2020; 10(1):26743. https://doi.org/10.32598/ijmtfm.v10i1.26743

dol https://doi.org/10.32598/ijmtfm.v10i1.26743

\section{(1) (\$)}

Article info:

Received: 11 Sep 2019

First Revision: 27 Sep 2019

Accepted: 03 Jan 2020

Published: 16 Feb 2020

\section{Keywords:}

Diaphragmatic paralysis, Pulmonary atelectasis, Pneumonia, Diabetic ketoacidosis

\section{ABSTRACT}

A 50-year-old woman was admitted to the emergency center with dyspnea, cough, and fever symptoms. She had a medical history of diabetes mellitus type II, rheumatoid arthritis, as well as several admission records due to aspiration pneumonia. The primary diagnosis was diabetic ketoacidosis and pneumonia. Normal breath sounds were reduced on the lower posterior right side of the thorax. A standard chest x-ray and lung Computed Tomography (CT) scan revealed collapse consolidation in the Right Lower Lobes (RLL) and Right Middle Lobes (RML). We here presented a case of unilateral diaphragmatic paralysis with a history of recurrent pneumonia.

\section{Introduction}

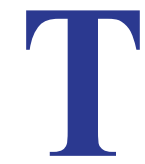

he diaphragm is the most crucial muscle of ventilation that poses negative intrathoracic pressure to initiate ventilation. The clinical features of diaphragm paralysis can be varied and linked to the etiology, unilateral or bilateral, acute or chronic conditions, and associated diseases. However, it may be a misdiagnosis of clinical conditions.

\section{Case history}

A 50-year-old woman complained about dyspnea, cough, and fever after admission to the emergency center. The recent symptoms initiated in the past several days. The vital signs were $\mathrm{T}=38.8 \mathrm{c}, \mathrm{BP}=126 / 90$ $\mathrm{mmHg}, \mathrm{PR}=105 \mathrm{per} / \mathrm{min}, \mathrm{RR}=23 \mathrm{per} / \mathrm{min}$, and Arterial Blood Gas (ABG) analysis included $\mathrm{PH}=7.26, \mathrm{PaCO}$ $=32.8 \mathrm{mmHg}, \mathrm{PaO} 2=34.9 \mathrm{mmHg}, \mathrm{HCO} 3=16.1$, and $\mathrm{O}_{2}$ sat $=52.9 \%$ at the time of administration without the use of supplemental $\mathrm{O}_{2}$. The other laboratory biochemi-

* Corresponding Author:

Farzaneh Sadat Mirsafai Rizi, MD.

Address: Internal Medicine Resident, Shahid Beheshti University of Medical Sciences, Logman Hakim General Teaching Hospital, Tehran, Iran Tel: +98 (913) 2391337

E-mail: amiri.es99@gmail.com 
cal tests consisted of $\mathrm{WBC}=14000$, segmented neutrophile $=93 \%, \mathrm{Hgb}=9,1 \mathrm{~g} / \mathrm{dL}$, Creatinin $=2,3 \mathrm{mg} / \mathrm{dL}$, blood sugar $=532 \mathrm{mg} / \mathrm{dL}, \mathrm{LDH}=592 \mathrm{u} / \mathrm{L}, \mathrm{CPK}=179 \mathrm{u} / \mathrm{L}, \mathrm{Na}$ $=126 \mathrm{meq} / \mathrm{L}, \mathrm{K}=4,1 \mathrm{meq} / \mathrm{L}, \mathrm{CL}=96 \mathrm{meq} / \mathrm{dL}$, and lactate level $=21 \mathrm{mg} / \mathrm{dL}$. The liver function test result was in the normal range.

The patient was referred to the endocrine ward for further evaluation. Insulin therapy and antibiotic therapy were initiated for the patient. Chest X-ray presented the homogenous density compatible with right hemidiaphragm that was associated with the malnormal position. Physical examination presented an increased dullness on the percussion of the right mid hemithorax and reduced normal breath sounds in the same region. The consultation was performed with a pulmonologist physician. She had a medical history of diabetes mellitus and rheumatoid arthritis. In addition, the patient reported several hospital admissions with a diagnosis of pneumonia.

Sputum culture was E-Coli, and antibiogram sensitive test results were amikacin, ciprofloxacin, cefepime, ceftazidime, cefuroxime, imipenem, and gentamycin. ESR and CRP were $63 \mathrm{~mm} / \mathrm{h}$ and $23 \mathrm{mg} / \mathrm{d}$, respectively.

The plain chest radiography identified an elevation of right hemidiaphragm near to the right hilum that was associated with adjacent alveolar shadows. Figure1 shows a plain chest X-ray of the patient. A CT scan revealed Right Middle Lobe (RML), and Lower Lobe (LL) collapses and no evidence of underlying malignancy, endobronchial mass, and mediastinal or hilar lymphadenopathy. Figure 2 discloses the conventional CT scan features of diaphragmatic paralysis.

The diaphragmatic paralysis was suggested. Fluoroscopy was executed with sniff maneuver. It was satisfied with the reduced function of hemidiaphragm with inspiration and expiration efforts without paradoxical movement.

Echocardiography was reported as Ejection Fraction (EF) $=40 \%$, mild Left Ventricular (LV) systolic dysfunction, and diastolic dysfunction grade I, mild global hypokinesia, and Pulmonary Artery Pressure (PAP) $=24$ $\mathrm{mmHg}$. Spirometry was carried out in the sitting position. The supine position was impossible for the patient. Its results were Vital Capacity $(\mathrm{VC})=47 \%$, Forced Vital Capacity $(\mathrm{FVC})=42 \%$, and Forced Expiratory Volume in One Second $(\mathrm{FEV} 1)=33 \%$.

\section{Discussion}

The diaphragm is a Greek word with two components; Dia=between and phragma $=$ fence. It has two distinct unite muscles with separate blood supply, innervation, and unique harmonic action. Muscle types of diaphragm fibers consisted of slow type I (fatigue resistant) and fast type II fibers equally [1]. The diaphragm has the ability to work in slow and fast conditions.

Diaphragm originates from the mesoderm layer in 4-12 gestation weeks of embryogenesis life. It consists of 4 components, Transverse Septum (TS), Pleuroperitoneal Fold (PPF), Esophageal Mesentery (EM), and Muscular Body Wall (MBW). Figure 3 shows the embryonic development of the diaphragm. The TS is a central tendon of the diaphragm, developed from dense collagen fibers. It supports the heart. The MBW attaches to the rib cage in the lower 6 ribs, and the main part of the diaphragm that acts on the outward displacement of the thorax and abdomen. Its function can increase lung volume and abdominal pressure. Morgagni (10\%) and Bochdalek (90\%) congenital hernias develop from a defect in the fusion of TS with the MBW and PPF, respectively [2, $3]$. Hiatuses are the normal opening foramina into the diaphragm. They cause the pass of Inferior Vena Cava (IVC hiatus), esophagus hiatus, and aortic hiatus. Figure 4 presents the anatomical position of the diaphragm.

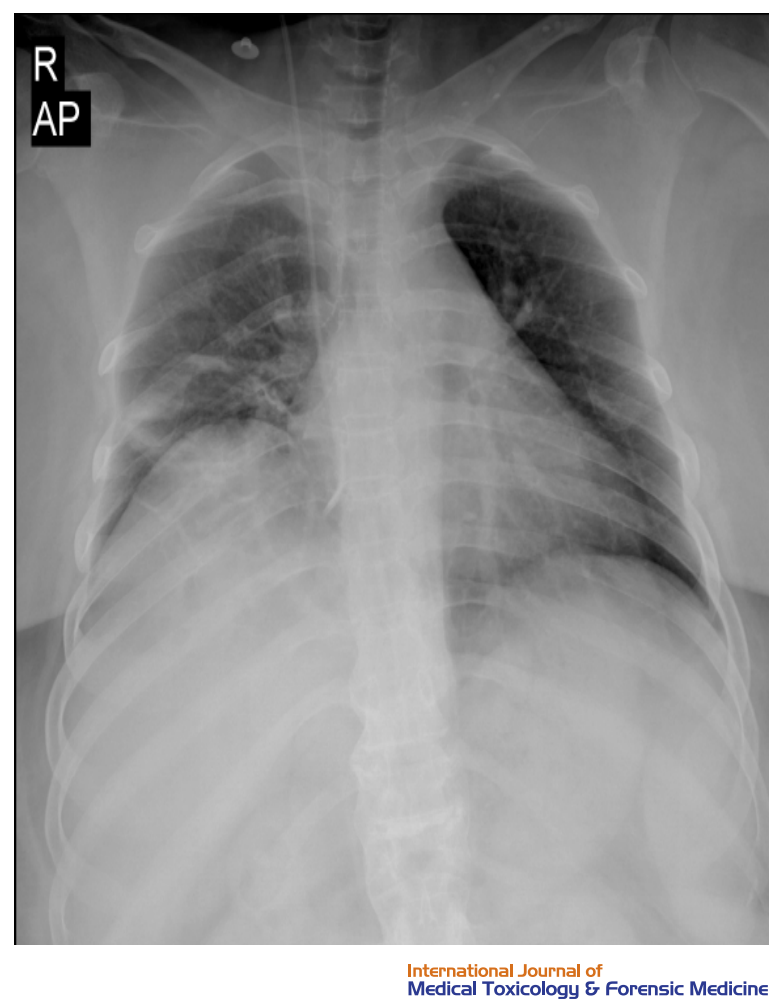

Figure 1. A plain chest $X$-ray of the study patient 

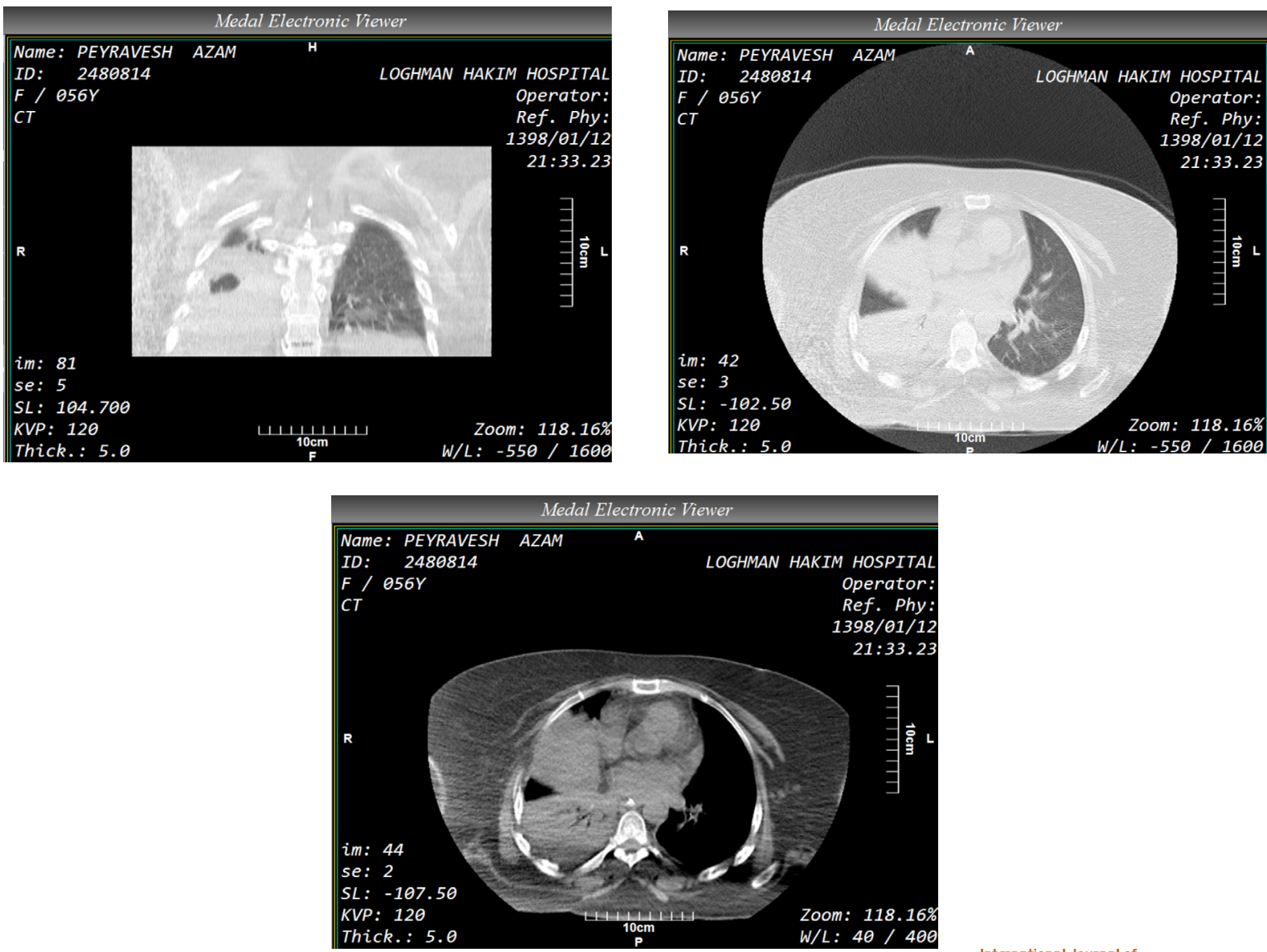

International Journal of
Medical Toxicology \& forensic Medicine

Figure 2. The conventional CT scan features of diaphragmatic paralysis evidence, coronal and sagittal views

The diaphragm is an important and the primary ventilatory muscle, providing $80 \%$ of the respiratory working of normal tidal breathing volume, a physical barrier separating the abdomen from thoracic cavities, and inducing negative pressure in the pleural space as a thoracoabdominal pump. In addition, it affects car- diac functions, venous and lymphatic return, indirectly assists with numerous physiological activities, such as emesis, urination, defecation, gastroesophageal reflux prevention, as well as the regulation of emotional state and pain threshold. However, the diaphragm supports maintaining lumbospinal stability through raised in-

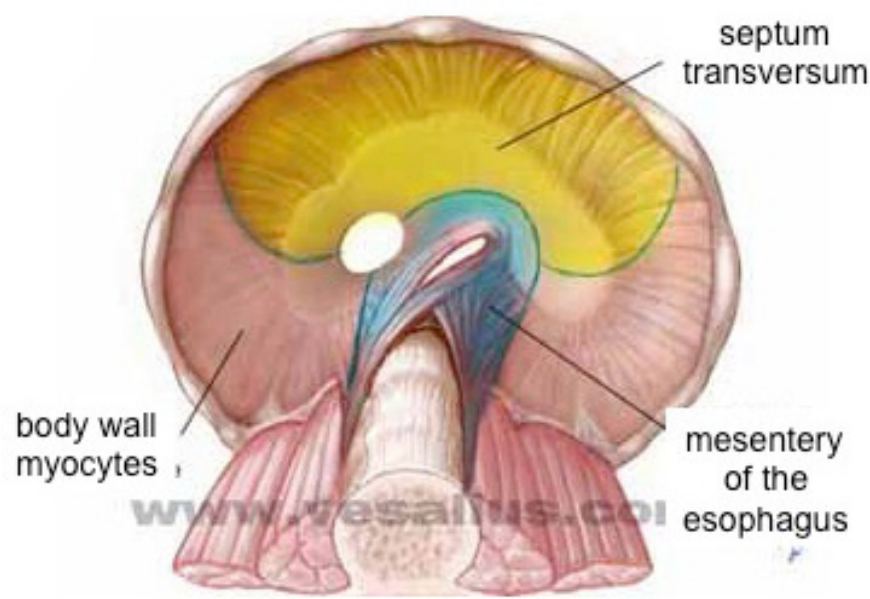

Figure 3. The embryogenic development of the diaphragm (reprinted from Google) 


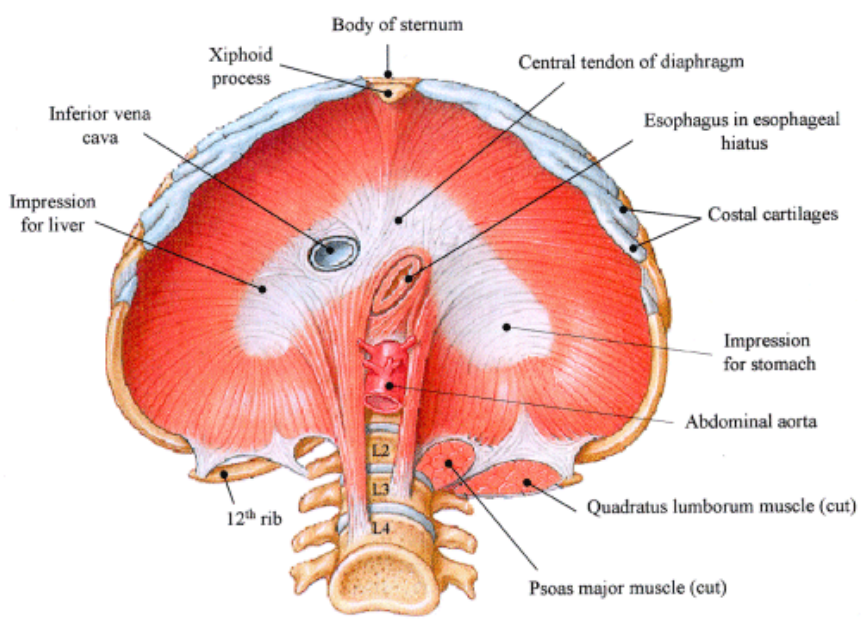

Figure 4. The anatomical position of the diaphragm (reprinted from Google)

International Journal of
Medical Toxicology \& Forensic Medicin

traabdominal pressure and has an anatomical connection with a spinal column by crural fibers [4]. Standard chest X-ray disclosed the more extended dome of the right hemidiaphragm, compared to the left side. Moreover, it declared the anterior and median portion of the diaphragm were higher than the median and posterior sides. Both domes supported the lung bases.
Diaphragmatic Dysfunction (DD) applies to any etiologic causes that may interfere with innervation, muscle function contraction, and any disorder's effect on the mechanical chest mechanism [5]. The DD accounts for eventration, partial muscle loss function (weakness), and the diaphragm paralysis
A

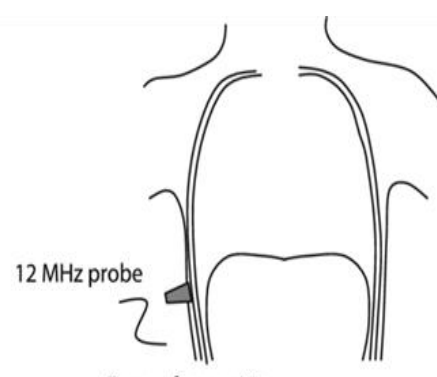

Zone of apposition

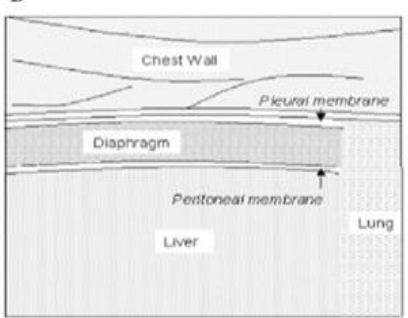

$T F=(T E I-T E E) / T E E$

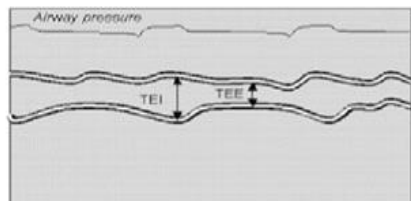

TEI, thickness at end inspiration; TEE, thickness at end expiration.
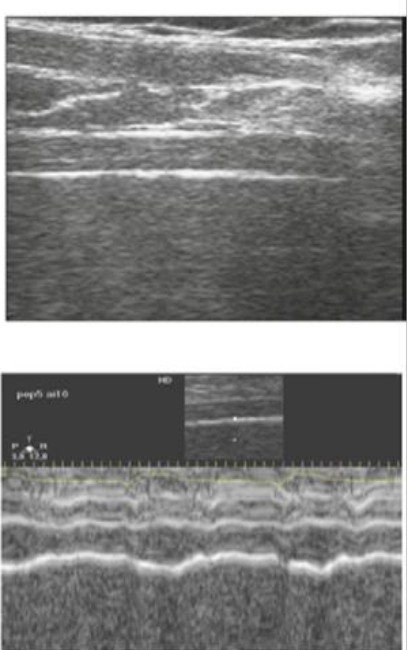

International Journal of
Medical Toxicology \& forensic Medicin

Figure 5. The ZOA position in relation to the rib cage and the diaphragmatic ultrasonography results (reprinted from Google) 


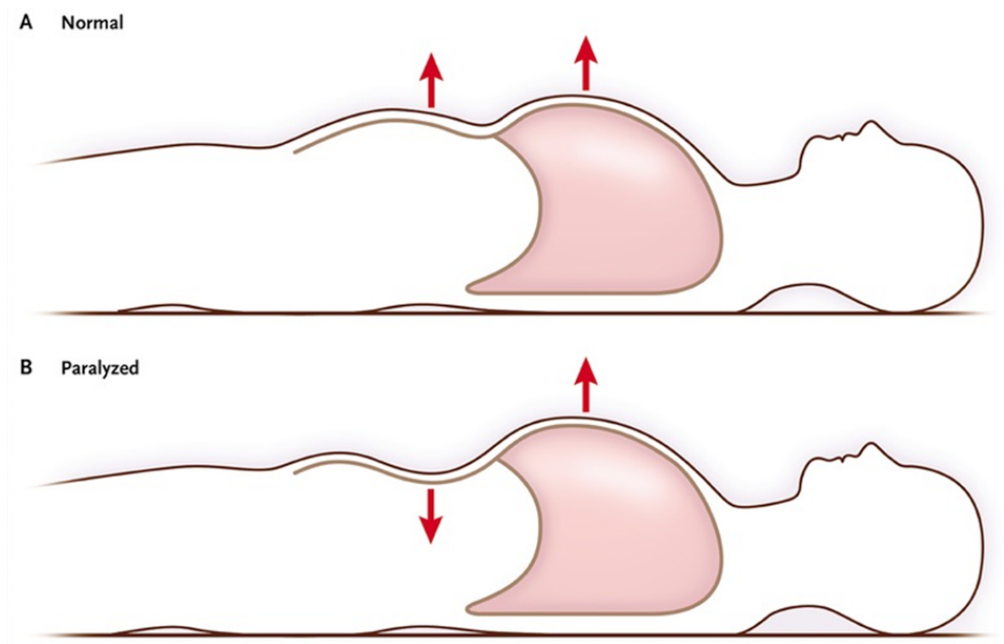

Figure 6. The schematic paradoxical movement of the diaphragm (reprinted from Google) $\quad \begin{aligned} & \text { International Journal of } \\ & \text { Medical Toxicology \& Forensic Medicine }\end{aligned}$

Palsy or paresis (weakness) and paralysis occur in some muscle fibers and whole neuromuscular axis, respectively. Weakness is the loss of partially muscle fiber that cannot produce adequate muscle pressure for ventilation. Paralysis is the total loss of the ability of pressure generation in diaphragmatic muscle. Eventration is the congenital thinning of diaphragmatic muscle and the involved segment. It is more common in the anterior and medial portions of the diaphragm and the right-sided.

Diaphragm's attachment area to the rib cage is called the Zone of Appositional (ZOA). Figure 5 manifests the ZOA position concerning the rib cage as well as the view of diaphragmatic ultrasonography results. It includes the muscle insertion of the xiphoid process, the lower 6 rib cartilages, and two first lombovertebral bodies [6]. It composes $40 \%$ of the rib cage and $60 \%$ of diaphragmatic muscle at end-expiration [7]. It has two major forces; insertional and oppositional ones. The first force exerts the pressure on the attachment of diaphragmatic muscles in the rib area cage, and the second force is generated by abdominal pressure that transmits to the ZOA. They are balanced in residual functional volume. Some diseases could affect the directions and pressure amount of recent forces, like Chronic Obstructive Pulmonary Disease (COPD) and quadriplegia. Inconsequently, it leads to a

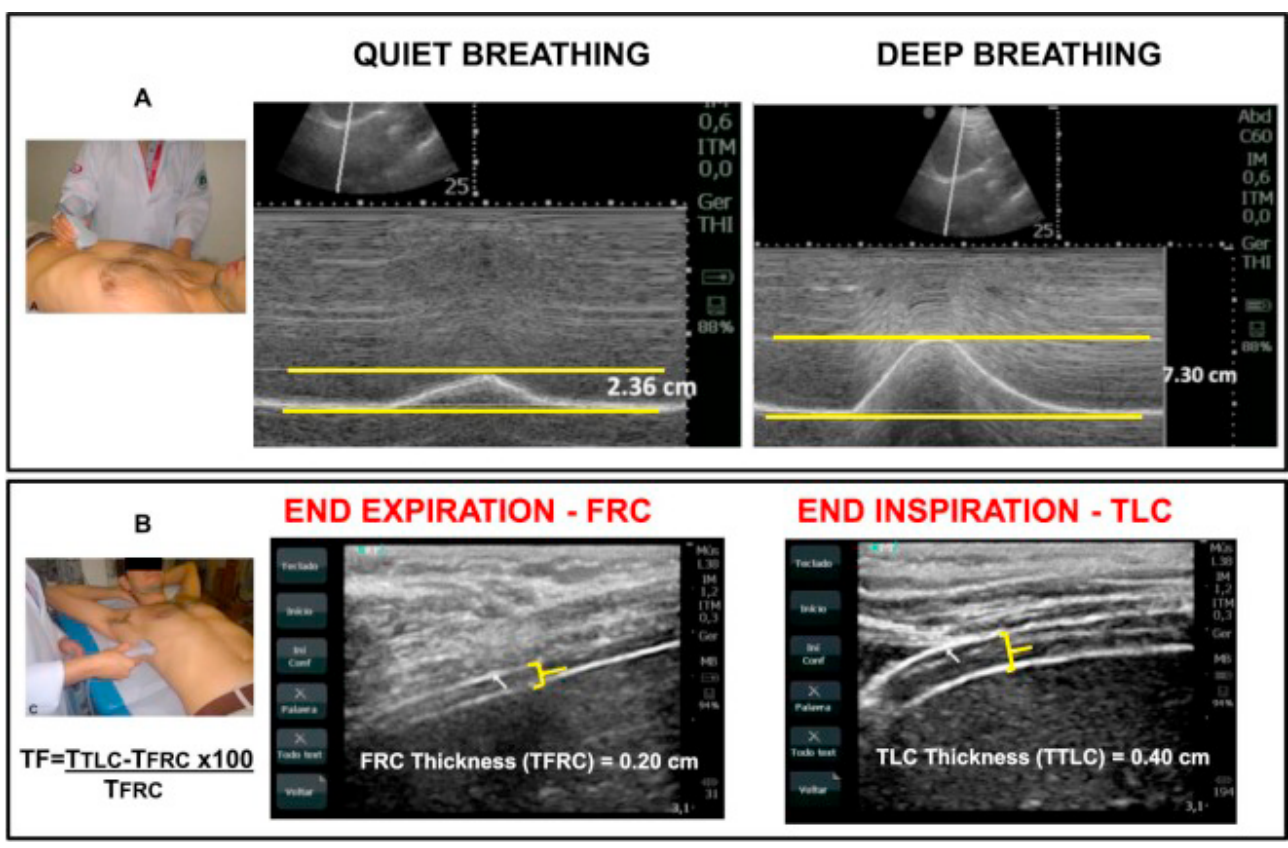

Figure 7. The ultrasonography of diaphragmatic paralysis features (reprinted from Google) 

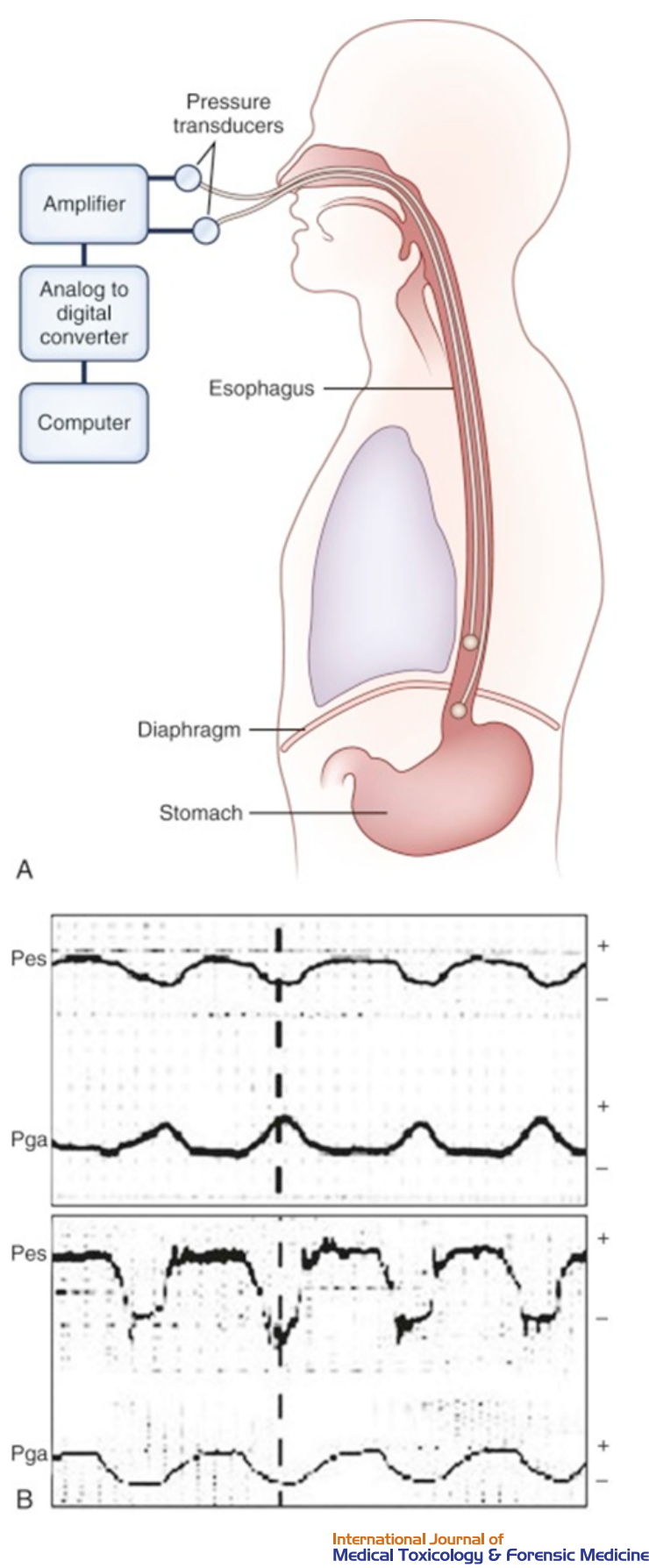

Figure 8. The transdiaphragmatic recording pressure (reprinted from Google)

change of pleural pressure and lung expansion. Our case was also admitted with respiratory failure.

The DD may be presented in clinical features as unilateral, bilateral, or from the duration point; it could be permanent, temporary, and intermittent. The Unilateral Diaphragmatic Paralysis (UDP) is more prevalent than the other types. It has less symptomatic discomfort and is usually detected incidentally [8]. Less than $17 \%-20 \%$ of UDP cases reported idiopathic [9]. It is more common on the right side than the left side and in females. Our studied case was female with right hemidiaphragm paralysis. The current data are compatible with the presented case.

Clinical features of DD have a strong relation with the etiology, comorbid condition diseases, the compensation mechanism function of other respiratory muscles, and clinical features presentation, such as unilateral or bilateral and partial or total loss of function. The causal factors of unilateral elevation include volume loss, eventration, abdominal disease, phrenic nerve paralysis, phrenoplasty, splinting, and mimicking false features, like subpulmonic pleural effusion. The etiology of bilateral diaphragmatic elevation may consist of phrenic nerve paralysis, volume loss, abdominal mass effect, neuromuscular diseases, and connective tissue diseases, and endocrine and metabolic diseases as electrolyte abnormalities and thyroid function disorders [3]. Diaphragm malposition may be manifested as depression level. It may be unilateral, such as pneumothorax asymmetrical bullous emphysema, large pleural effusion, body aspiration, and congenital lobar emphysema. It might also be bilateral, including COPD, massive bilateral pleural effusion, large bilateral pneumothorax, high-pressure mechanical ventilation, cystic fibrosis, pulmonary histiocytosis $\mathrm{X}$, and lymphangioleiomyomatosis3.

Unilateral Diaphragmatic Dysfunction (UDD) is usually asymptomatic in the clinic. The patient may complain of exertional dyspnea, orthopnea, and susceptibility to respiratory infection (diaphragm immobility). Our studied case reported a history of recurrent pulmonary infection and a diabetes mellitus background. Bilateral Diaphragmatic Paralysis (BDP) may be associated with respiratory failure, hypoxemia, hypoventilation, and sleeping disturbance that may gradually lead to rightsided heart failure [10].

Evaluating DD is suggested by one or several of the following tests: chest $\mathrm{x}$-ray, fluoroscopic test, thorax ultrasound, chest computed tomography, Pulmonary Function Test (PFT), Maximum Inspiratory Pressure (MIP), and transdiaphragmatic pressure.

PFT discloses diaphragmatic paralysis and diaphragmatic palsy. Spirometry is performed in sitting and supine positions; differences in vital capacities are measured concerning patient predicted. Suggested spirometry data include UDP (VC>70\% and decreased supine position $>15 \%$ ) and $\mathrm{BDP}$ ( $\mathrm{VC}<50 \%$ and decreased supine position $>30 \%) 5$. CT scan is carried out for detecting the pathological causes of DD. It is performed in inspiration and expiration efforts. 
Fluorescent test or sniff test is among the oldest techniques for the visualization of diaphragmatic movement and requires patient's cooperation. It has a risk of ionizing radiation, performing in the supine position, and intoleration by the bilateral DP with orthopnea. Patients with DP demonstrate no movement in inspiration in the opposite direction (paradoxical) in sniff maneuver. Figure 6 represents the schematic paradoxical movement of the diaphragm.

MIP is generated against the closed mouthpiece. It presents the forces of all respiratory muscle actions. MIPs $>80 \mathrm{cms}$ exclude the DP. MIPs $>60-70$ and $<40 \mathrm{~cm}$ suggest the UDP and BDP, respectively [5].

Ultrasonography is a new technique of diaphragmatic thickness evaluation with feasible execution and portability, particularly in the ICU. It performs by M-mode and $7.5 \mathrm{~Hz}$ linear convex probe for evaluating excursion and B-mode $(3.5 \mathrm{~Hz})$ for measuring the thickness. The diaphragm is presented with three layers in ultrasound; one non-echogenic (diaphragm) in the middle zone and two echogenic (premium and plural) ones in the outer zone. Thickness $<15 \mathrm{~mm}$ or thickness fraction (TF\%) $>20$ are cutoff points suggesting diaphragmatic weakness (Figure 5) [11]. Figure 7 displays the ultrasonography of diaphragmatic paralysis features.

Transdiaphragmatic pressure (Tdpdi $\mathrm{cm} \mathrm{H}_{2} \mathrm{O}$ ) measurement is an invasive technique. It estimates the pressure difference between gastric (intraabdominal pressure) and esophageal (intrathoracic pressure) parts and is a gold standard test for DP evaluation [12]. The very low or near zero pressure difference support the DP presence. Tdpdi $>70$ and $<40 \mathrm{~cm} \mathrm{H}_{2} \mathrm{O}$ reveal the UDP and BDP, respectively, 5 [13]. Figure 8 demonstrated the transdiaphragmatic recording pressure.

Treatment of DP is recommended with inspiratory muscle training. UP may not require any treatment and most of them recover during the time; however, they may rarely require an advanced stage to nocturnal breathing support and plication surgery.

BD Weakness (BDW) patients may be required to use positive-pressure ventilation based on the reconstruction. The most advanced BDW conditions are supported by tracheostomy and mechanical ventilation. Selected patients with intact phrenic nerve are candidates for phrenic nerve stimulation technique.

\section{Conclusion}

Unilateral diaphragmatic paralysis is among the less commonly considerable clinical conditions. It can cause misinterpretations in clinical judgment. However, it also causes comorbid diseases and is associated with some degree of respiratory failure in the long-term.

\section{Ethical Considerations}

\section{Compliance with ethical guidelines}

All the authors met the criteria of authorship based on the recommendations of the international committee of medical journal editors.

\section{Funding}

This research did not receive any specific grant from funding agencies in the public, commercial, or not-forprofit sectors.

\section{Author's contributions}

Managing of medical team: Akram Sabkara; Corresponding author, and data gathering: Farnazosadat MirSafai Rizi; Consultant of the patient, designing and editing the article: Khosrow Agin.

\section{Conflict of interest}

There were no conflicts of interest to be declared.

\section{Acknowledgements}

The authors thank the Endocrinology and Pulmonology departments of Loghman Hakim general teaching hospital.

The authors also thank the patient who allowed us to use her disease information.

\section{Referances}

[1] Kokatnur L, Rudrappa M. Diaphragmatic palsy. Diseases. 2018; 6(1):pii:E16. [DOI:10.3390/diseases6010016] [PMID] [PMCID]

[2] Nason LK, Walker CM, McNeeley MF, Burivong W, Fligner CL, Godwin JD. Imaging of the diaphragm: Anatomy and function. Radiographics. 2012; 32(2):E51-70. [DOI:10.1148/ rg.322115127] [PMID]

[3] Koo CW, Johnson TF, Gierada DS, White DB, Blackmon S, Matsumoto JM, et al. The breadth of the diaphragm: Up- 
dates in embryogenesis and role of imaging. The British Journal of Radiology. 2018; 91(1088):20170600. [DOI:10.1259/ bjr.20170600] [PMID] [PMCID]

[4] Kocjan J, Gzik-Zroska B, Nowakowska K, Burkacki M, Suchoń S, Michnik R, et al. Impact of diaphragm function parameters on balance maintenance. PLOS One. 2018; 13(12):e0208697. [DOI:10.1371/journal.pone.0208697] [PMID] [PMCID]

[5] Ricoy J, Rodríguez-Núñez N, Álvarez-Dobaño JM, Toubes ME, Riveiro V, Valdés L. Diaphragmatic dysfunction. Pulmonology. 2019; 25(4):223-35. [DOI:10.1016/j.pulmoe.2018.10.008] [PMID]

[6] Bains KNS, Lappin SL. Anatomy, Thorax, Diaphragm. New York: StatPearls; 2019.

[7] Troyer AD, Wilson TA. Action of the diaphragm on the rib cage. Journal of Applied Physiology. 2016; 121(2):391-400. [DOI:10.1152/japplphysiol.00268.2016] [PMID]

[8] Kokatnur L, Rudrappa M. Diaphragm, Disorders. StatPearls. New York: StatPearls Publishing; 2019.

[9] Elefteriades J, Singh M, Tang P, Siegel MD, Kenney B, Pandey A, et al. Unilateral diaphragm paralysis: Etiology, impact, and natural history. The Journal of Cardiovascular Surgery. 2008; 49(2):289-95. [PMID]

[10] Steier J, Jolley CJ, Seymour J, Kaul S, Luo YM, Rafferty GF, et al. Sleep-disordered breathing in unilateral diaphragm paralysis or severe weakness. European Respiratory Journal. 2008; 32(6):1479-87. [DOI:10.1183/09031936.00018808] [PMID]

[11] Vetrugno L, Guadagnin GM, Barbariol F, Langiano N, Zangrillo $\mathrm{A}$, Bove $\mathrm{T}$. Ultrasound imaging for diaphragm dysfunction: A narrative literature review. Journal of Cardiothoracic and Vascular Anesthesia. 2019; 33(9): 2525-36. [DOI:10.1053/j. jvca.2019.01.003] [PMID]

[12] Benditt JO. Esophageal and gastric pressure measurements. Respiratory Care. 2005; 50(1):68-75. [PMID]

[13] McCool FD, Tzelepis GE. Dysfunction of the diaphragm. The New England Journal of Medicine. 2012; 366(10):932-42. [DOI:10.1056/NEJMra1007236] [PMID] 